\title{
Potential for a paradigm change in the detection of retinopathy of prematurity requiring treatment
}

\author{
Clare Gilbert, ${ }_{1}^{1}$ Richard Wormald, ${ }^{2}$ Alistair Fielder, ${ }^{3}$ Ashok Deorari, ${ }^{4}$ \\ Luz Consuelo Zepeda-Romero, ${ }^{5}$ Graham Quinn, ${ }^{6}$ Anand Vinekar, ${ }^{7}$ \\ Andrea Zin, ${ }^{8}$ Brian Darlow ${ }^{9}$
}

\section{THE INCREASING INCIDENCE OF BLINDNESS DUE TO RETINOPATHY OF PREMATURITY}

Retinopathy of prematurity (ROP) is a major cause of potentially avoidable blindness in children in the middle-income countries of Latin America and Eastern Europe, and is becoming a public health problem in Asia. ${ }^{1}$ Indeed, the earlier estimate that there were 50 000-60 000 children worldwide who were blind from $\mathrm{ROP}^{2}$ is a marked underestimate, as a recent systematic review suggests that annually 20000 infants (uncertainty range 15 500-27 200) became blind or severely visually impairment from ROP worldwide in 2010, with a further 12300 (8300-18 400) being visually impaired. ${ }^{3}$ Asia has the highest number, reflecting the rapid expansion of services for preterm infants in the region. ${ }^{4}$ The rate of severe visual loss from ROP is 1.8-2.6 times higher per million births in East Asia, the Pacific region, Latin America and Eastern Europe than in high-income countries, reflecting both a higher incidence of severe ROP and inadequate detection and treatment.

The recognition that prematurity is a major cause of infant and under five mortality rates ${ }^{6}$ is leading to rapid expansion

\footnotetext{
${ }^{1}$ Department of Clinical Research, London School of Hygiene \& Tropical Medicine, London, UK; ${ }^{2}$ Cochrane Eyes and Vision Group, London School of Hygiene \& Tropical Medicine, London, UK; ${ }^{3}$ Division of Optometry \& Visual Science, City University, London, UK; ${ }^{4}$ Department of Neonatology, All India Institute of Medical Sciences, Delhi, India; ${ }^{5}$ Department of Ophthalmology, Hospital Civil de Guadalajara, Guadalajara, Mexico; ${ }^{6}$ Division of Ophthalmology, Children's Hospital of Philadelphia, University of Pennsylvania Perelman School of Medicine, Philadelphia, USA; ${ }^{7}$ Department of Pediatric Retina, Narayana Nethralaya Postgraduate Institute of Ophthalmology, Bangalore, India; ${ }^{8}$ Department of Clinical Research, Child and Maternal Health, Instituto Fernandes Figueira, Fundação Oswaldo Cruz (Fiocruz), Rio de Janeiro, Brazil; ${ }^{9}$ Department of Paediatrics, University of Otago, Christchurch, New Zealand

Correspondence to Dr Clare Gilbert, Department of Clinical Research, London School of Hygiene \& Tropical Medicine, Keppel Street, London WC1E 7HT, UK; clare.gilbert@Ishtm.ac.uk
}

of neonatal care in many countries such as India, ${ }^{7}$ China and Russia, which will put an increasing number of infants at risk of ROP. Visual loss from ROP will continue to increase in low-income and middle-income countries with improving preterm survival rates unless there are dramatic improvements in neonatal care coupled with higher coverage of highquality services for the detection and treatment of ROP.

\section{PROGRAMMES FOR ROP IN LOW-INCOME AND MIDDLE-INCOME COUNTRIES}

The vast majority of programmes for the detection and treatment of ROP rely on highly skilled ophthalmologists who visit neonatal units on a weekly basis, or more frequently, to examine infants at risk. Many middle-income countries have criteria for examination, often drawn up collaboratively by professional societies of ophthalmologists and neonatologists, and programmes are becoming integrated into health systems. Many use criteria based on local evidence of the population of infants at risk, which in many resourcepoor settings includes more mature infants than those examined in the UK, for example, those with birth weights (BWs) in the range 1500-2000 g or gestational ages (GA) above 31 weeks. ${ }^{8}$

\section{FAILURE OF ROP PROGRAMMES}

Taking a programmatic perspective, there are many reasons why infants may become blind from ROP. First, infants may have received care in a unit without services for the detection and/or treatment of ROP. Second, infants with BWs and GAs that exceed criteria for examination, but who fall within 'sickness criteria', may not be examined, as these criteria are usually not clearly defined or straightforward to apply. Third, the infant may have been identified as requiring examination, but this was not carried out effectively, that is, the interval between examinations was too long, or the signs of ROP were not adequately determined or interpreted, or the infant was deemed too sick for examination. Administrative errors or poor communication can also lead to failure of examination after discharge or transfer between neonatal units. Inadequate communication with parents or parents who lack the resources to travel back to the unit on the requisite day after discharge may also result in failure to detect ROP needing treatment. Lastly, ROP requiring treatment may have been detected, but the treatment was not successful (eg, laser treatment was inadequate, or the infant had rapidly progressing disease, which did not respond to adequate treatment), or treatment was not given, or was delayed because of lack of anaesthesia, skilled personnel or equipment, or the infant was too sick. All these different reasons have been cited. ${ }^{10-14}$ Indeed, a recent study of 48 infants who presented with stage 5 ROP to an eye department in a major city in Mexico over a 2-year period revealed that $50 \%$ had been cared for in a unit without an ROP programme. Among the 24 infants who were cared for in units with a programme, $15 \%$ of mothers reported that their infant had not been examined, and $19 \%$ of infants were either not referred for examination after discharge, or they did not attend. ${ }^{10}$ This is despite Mexico having national guidelines for ROP and legislation making eye examination of all preterm infants mandatory. In a further study in Mexico involving 32 units in five major cities, $34 \%$ of units had no programme for the detection and treatment of ROP, and only $31 \%$ of programmes entailed regular visits by an ophthalmologist, with laser treatment being provided in the unit if indicated. $^{15}$

In many middle-income countries, there is a complex interplay of economic, political and personal reasons why services for the detection and treatment of ROP are not in place in all neonatal units. Some ministries of health are not aware of the serious, potentially avoidable complications of preterm birth, and so, policies are not in place to address them, or they face competing demands and prioritise life-threatening conditions. Other countries have highly complex health systems with multiple providers and insurance schemes, which make implementing uniform policies and practices very challenging. Studies highlight the challenges of ophthalmologist-led programmes, which include long distances between units, fear of litigation, lack of time or interest in taking on ROP and lack of financial remuneration, some of which also apply to high-income settings. ${ }^{16}$ 
Programmes that use regular retinal imaging with or without remote interpretation of images have the potential to increase coverage, but any approach that relies on visits by personnel external to the neonatal service, such as ophthalmologists, can only address some of the problems. An additional important factor is that there is currently only one wide-field retinal camera suitable for ROP (RetCam, Clarity), which is very expensive. In order to address the rapidly expanding population of babies at risk of ROP and the challenges faced by health providers (neonatal care and eye care) and parents, a paradigm shift in the detection of acute ROP needing treatment is required, which uses screening in the true sense of the word. This would require new, low cost, widefield imaging technology, as visualisation of the peripheral retinal vasculature is essential for making the management decision that no further retinal examinations are required, which is not yet available. But first, consideration of the term screening is required.

\section{SCREENING FOR ROP}

Screening is defined as 'a process of identifying apparently healthy people who may be at increased risk of the disease or the condition [of interest]. They can then be offered information, further tests and appropriate treatment to reduce their risk and/or any complications arising from the disease or condition'. ${ }^{17}$ A screening programme requires a simple, valid, noninvasive, acceptable and inexpensive test, which is applied to the population at risk. Those who fail the screening test require clinical assessment to confirm the diagnosis, followed by treatment if indicated. Another requirement of screening programmes is that earlier treatment of the condition leads to better outcomes. Ophthalmology-led programmes for ROP are not, therefore, screening programmes in the strict sense of the word as diagnostic examinations are performed with clinical decisions at each visit (figure 1).

Screening for ROP requiring treatment differs from screening for chronic diseases such as breast, cervical or prostate cancer or diabetic retinopathy, or screening for metabolic disorders where a one-off test is required. First, the population at risk is defined by BW, GA and the services received (ie, neonatal care) and not by chronological age, gender or disease status (eg, diabetes). Second, there is a very narrow time interval during which severe ROP develops (ie, from 3 to 18 weeks after birth depending on GA). Third, there is not a simple pass/fail test as each assessment requires a management decision, which has three options: (1) no further examination is required as the retinal vessels are mature or ROP is definitely regressing, or (2) further examination is required after an interval to be decided by the screener (3-4 days or up to 2 weeks), or (3) treatment is required, which should be given within $48 \mathrm{~h}$.

\section{THE PARADIGM CHANGE REQUIRED}

Given the challenges and limitations of current programmes, there is an urgent need for a change in approach, which will become possible in the foreseeable future as low-cost high-quality imaging systems suitable for ROP become available (ie, with a wide field of view). Indeed, several groups are developing wide-field imaging systems suitable for ROP screening. Ideally, each unit would have its own imaging system, which would allow a neonatology-led approach to screening for ROP (figure 1). Ideally, a member of the clinical neonatal team or a trained technician would take and interpret images immediately at the cot-side. Only those infants with clearly defined indications would be referred for an urgent ophthalmic opinion. Putting the responsibility for screening in the hands of the neonatal team has considerable advantages as infants can be screened at a time that is convenient and when infants return for follow-up after discharge regardless of the day of the week. Immediate, on-site interpretation would also be highly desirable, so mothers of discharged infants can be given the management decision straight away. Immediate interpretation also does not require fast internet connections for remote interpretation, which is particularly important in low-income and middle-income settings where mothers of preterm infants may live many hundreds of miles away from the unit, and where many mothers are relatively uneducated, unmarried, uninformed and/or are teenagers.

The utility of this approach is supported by a multicentre study in the USA $^{18}$ where trained non-physician readers demonstrated high levels of validity in detecting 'referral-warranted ROP' (as defined by Ells) ${ }^{19}$ by remote viewing of digital images obtained by nonphysician imagers. Others have also demonstrated that neonatal nurses can reliably capture images. ${ }^{20}$ In a large-scale programme in India, trained non-medical technicians visit neonatal units on a weekly basis where they take and interpret the images, only sending images for remote interpretation by experts when they suspect referral-warranted ROP. The role of non-ophthalmologists in screening has been advocated by Trese, ${ }^{21}$ and the Indian programme has demonstrated that technicians can also achieve high levels of validity. ${ }^{22}$ Both studies indicate the potential role of imaging by nonophthalmologists in increasing the coverage of screening for ROP regardless of the setting. Indeed, the authors of a recent joint report from the American Academy of Pediatrics Section on Ophthalmology, the American Academy of Ophthalmology and the American Association of Certified Orthoptists support the role of telemedicine with remote image analysis in surveillance for referral-warranted $\mathrm{ROP}^{23}$

There are further advantages of neonatology-led screening, as ophthalmologists would only need to visit units to examine the relatively small number of infants developing severe ROP. This is likely to increase the number of ophthalmologists willing to provide services for ROP and greatly reduces their costs, so improving cost-effectiveness. There would be advantages for parents of discharged infants as they would not have to bring their child back to coincide with the visit by the ophthalmologist. Images can also be used to train staff and to raise awareness among parents. A permanent record of the retina also allows progression or regression of disease to be more readily detected, and can be used for medicolegal purposes. Automatic image analysis systems are being developed, which have the potential to augment or back up a neonatology-led programme. ${ }^{24}$

\section{IMPLICATIONS FOR NEONATOLOGY-LED SCREENING FOR ROP}

There are several important factors to consider in establishing a neonatology-led programme. First, a change in mindset will be required among neonatologists and ophthalmologists, and clearly defined roles and responsibilities will need to be established, recognising that close collaboration and clear lines of communication between neonatologists and ophthalmologists will continue to be essential. Personnel, be they medical, paramedical or technicians, will need to be trained to reach high levels of competency and maintain this level through quality assurance measures. In the Indian programme outlined above, Vinekar has developed competency-based training for the technicians, delineating the skills required across a range of activities: the technicians can only make independent management decisions once they have reached the highest 


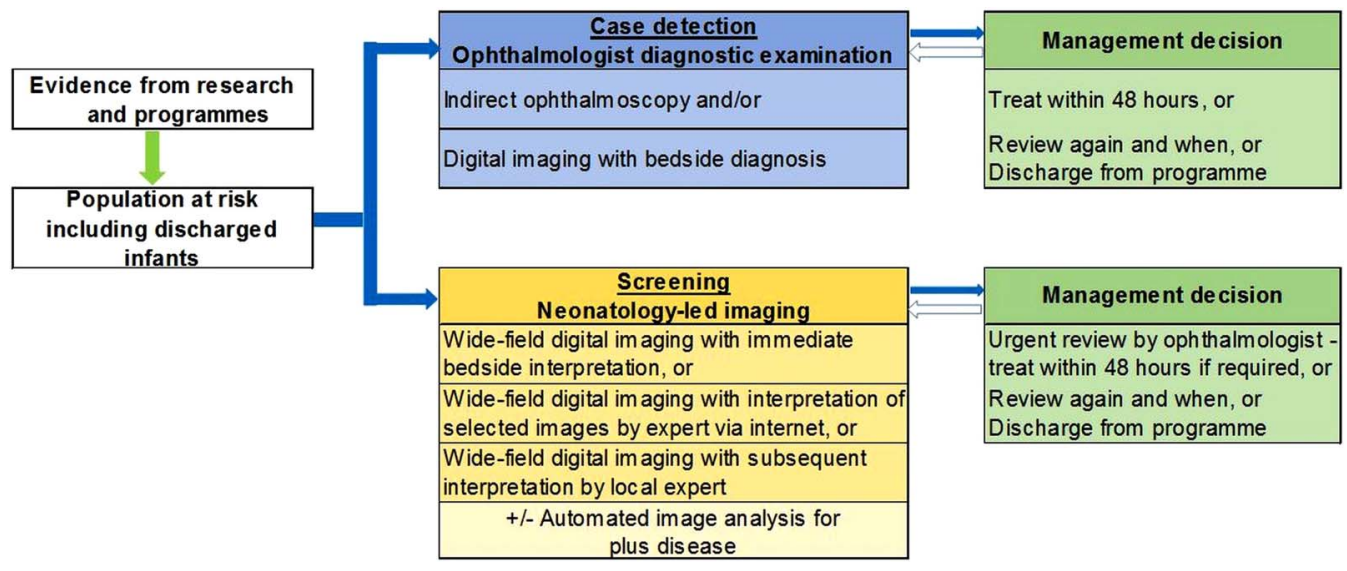

Figure 1 Comparison of ophthalmology-led and neonatology-led approach to detecting retinopathy of prematurity.

level of competency. ${ }^{22}$ More than one person per unit will need to be trained to cover annual leave, illness and personnel changes.

Ophthalmologists with skills in diagnosing and treating ROP will still be required, with clear indications concerning which neonatal units they will be responsible for. Advocacy with ministries of health will be required for policy change so that any new retinal imaging system becomes essential equipment for neonatal intensive care, and additional staff may also be required. The medicolegal implications of screening by non-ophthalmologists will also have to be addressed, as will licensing.

Screening and treating ROP is highly cost-effective. The incremental cost of a neonatology-led service may be lower than that estimated for the ophthalmology-led service in Brazilian Government's municipal health service for neonatal care where the cost for ophthalmologists to visit and examine all eligible infants for ROP would increase the cost of providing neonatal care by $10 \% .^{25}$

Some lessons can be learnt from clinician-led echocardiography (using Doppler sonography), which has become more readily available since the development of affordable equipment. However, the situation is not entirely parallel to neonatology-led screening for ROP as echocardiography is not used to screen for cardiac abnormalities, but as an adjunct to clinical diagnosis and to monitor treatment. ${ }^{26}$ Echocardiography is now often performed by neonatologists or paediatricians rather than by paediatric cardiologists or radiologists. However, several issues have arisen, some of which have hindered more widespread adoption of clinician-led echocardiography. The main issues relate to professional boundaries, the nature and content of competency-based training, ${ }^{27}$ medicolegal issues and remuneration. Another issue that remains controversial is the lack of robust evidence from clinical trials of the impact of clinician-led echocardiography. ${ }^{28}$ However, some argue that clinical trials are not required to assess the effectiveness of echocardiography as the main question is diagnostic accuracy.

In neonatology-led screening for ROP, competency-based training would be required, recognising that acquiring new skills and capabilities requires experience and supervision. The indications for referral for an ophthalmic opinion devised by Ells $^{19}$ may also need to be simplified. In terms of diagnostic accuracy, studies would be needed to compare the accuracy of interpretation of retinal images by a member of the neonatal team compared with the gold standard, that is, indirect ophthalmoscopy by an ophthalmologist with experience in ROP. In these studies, it will be important to assess the validity of the management decisions as well as the validity of the clinical signs of ROP elicited. Medicolegal issues would need to be addressed by clearly defining where the burden of responsibilities lies from initial identification of infants at risk through to timely treatment of severe disease. Difficulties in relation to professional boundaries may arise, but one of the main challenges, which limits increase in coverage of programmes for the detection of severe ROP, is the lack of ophthalmologists with the relevant expertise, interest or time to visit neonatal units on a regular basis. Close collaboration between the team on the neonatal unit and ophthalmologists will continue to be vital to the control of visual loss from ROP.

Contributors CG conceptualised the paper and wrote the first draft and finalised the manuscript. RW, $A F$, $A D, L C Z-R, G Q, A V, A Z$ and $B D$ gave intellectual input to the manuscript and commented on drafts.
Competing interests None declared.

Provenance and peer review Not commissioned; externally peer reviewed.

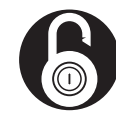

\section{OPEN ACCESS}

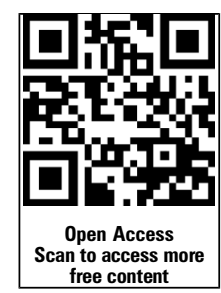

Open Access This is an Open Access article distributed in accordance with the Creative Commons Attribution Non Commercial (CC BY-NC 4.0) license, which permits others to distribute, remix, adapt, build upon this work non-commercially, and license their derivative works on different terms, provided the original work is properly cited and the use is noncommercial. See: http://creativecommons.org/licenses/ by-nc/4.0/

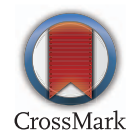

To cite Gilbert $\mathrm{C}$, Wormald R, Fielder A, et al. Arch Dis Child Fetal Neonatal Ed 2016;101:F6-F9.

Received 31 March 2015

Revised 15 June 2015

Accepted 5 June 2015

Published Online First 24 July 2015

Arch Dis Child Fetal Neonatal Ed 2016;101:F6-F9. doi:10.1136/archdischild-2015-308704

\section{REFERENCES}

1 Gilbert C, Fielder A, Gordillo L, et al, on behalf of the International NO-ROP Group. Characteristics of babies with severe retinopathy of prematurity in countries with low, moderate and high levels of development: implications for screening programmes. Pediatrics 2005; 115:518-25.

2 Gilbert C. Retinopathy of prematurity: a global perspective of the epidemics, population of babies at risk and implications for control. Early Hum Dev 2008:84:77-82.

3 Blencowe $\mathrm{H}$, Lawn JE, Vazquez $\mathrm{T}$, et al. Preterm associated visual impairment and estimates of retinopathy of prematurity at regional and global level for 2010. Pediatric Res 2013;54: 36-49. 
4 Sun B, Shao X, Cao Y, et al. Neonatal-perinatal medicine in a transitional period in China. Arch Dis Child Fetal Neonatal Ed 2013;98:F440-4.

5 Neogi SB, Malhotra S, Zodpey S, et al. Challenges in scaling up of special care newborn units-lessons from India. Indian Pediatr 2011:48:931-5.

6 Howson CP, Kinney MV, Lawnm JE, Eds. March of Dimes, PMNCH, Save the Children, WHO. Born Too Soon: The Global Action Report on Preterm Birth. Geneva: World Health Organization, 2012.

7 Sundaram V, Chirla D, Panigrahy N, et al. Current status of NICUs in India: a nationwide survey and the way forward. Indian J Pediatr 2014:81:1198-204.

8 Zin A, Florêncio T, Fortes Filho JB, et al. [Brazilian guidelines proposal for screening and treatment of retinopathy of prematurity (ROP)]. Arq Bras Oftalmol 2007;70:875-83.

9 Chile guidelines Ministerio de Salud. Guía clínica retinopatía del prematuro. Santiago: Minsal, February 2010. http://web.minsal.cl/portal/url/item/ 721fc45c973b9016e04001011f0113bf.pdf

10 Zepeda-Romero LC, Meza-Anguiano A, Barrera-de León $\mathrm{JC}$, et al. Case series of infants presenting with end stage retinopathy of prematurity to two tertiary eye care facilities in Mexico: underlying reasons for late presentation. Matern Child Health J 2015;19: 1417-25.

11 Zin A, Lopes B, Bunce C, et al. Retinopathy of prematurity in 7 neonatal units in Rio de Janeiro, Brazil: screening criteria and workload implications. Pediatrics 2010;126:e410-17.

12 Urrets-Zavalia JA, Crim N, Knoll EG, et al. Impact of changing oxygenation policies on retinopathy of prematurity in a neonatal unit in Argentina. Br J Ophthalmol 2012;96:1456-61.
13 Attar MA, Gates MR, latrow AM, et al. Barriers to screening infants for retinopathy of prematurity after discharge or transfer from a neonatal intensive care unit. J Perinatol 2005;25:36-40.

14 Aprahamian AD, Coats DK, Paysse EA, et al. Compliance with outpatient follow-up recommendations for infants at risk for retinopathy of prematurity. J AAPOS 2000;4:282-6.

15 Zepeda Romero CL, Gilbert C. Limitations in ROP programs in 32 neonatal intensive care units in five States in Mexico. BioMed Res Int 2015;2015:712624.

16 Kemper AR, Wallace DK. Neonatologists' practices and experiences in arranging retinopathy of prematurity screening services. Pediatrics 2007;120: 527-31.

17 National Health Service, UK. What is screening? http://www.screening.nhs.uk/screening (accessed Oct 2014).

18 Quinn GE, Ying GS, Daniel E, et al, for the e-ROP Cooperative Group. Validity of a telemedicine system for the evaluation of acute-phase retinopathy of prematurity. JAMA Ophthalmol 2014;132: 1178-84.

19 Ells AL, Holmes JM, Astle WF, et al. Telemedicine approach to screening for severe retinopathy of prematurity: a pilot study. Ophthalmology 2003:110:2113-17.

20 Fijalkowski N, Zheng LL, Henderson MT, et al. Stanford University Network for Diagnosis of Retinopathy of Prematurity (SUNDROP): five years of screening with telemedicine. Ophthalmic Surg Lasers Imaging Retina 2014;45:106-13.

21 Trese MT, Denisova EV, Katargina LA. Telemedicine with smart software for retinopathy of prematurity screening; experience from a programme in the US and prospects for use. Russian Ped Ophthalmol 2014;2:5-8

22 Vinekar A, Gilbert C, Dogra M, et al. The KIDROP model of combining strategies for providing retinopathy of prematurity screening in underserved areas in India using wide-field imaging, tele-medicine, non-physician graders and smart phone reporting. Indian J Ophthalmol 2014;62: 41-9.

23 Fierson MF, Capone A, the American Academy of Pediatrics Section on Ophthalmology, the American Academy of Ophthalmology, and the American Association of Certified Orthoptists. Telemedicine for Evaluation of Retinopathy of Prematurity. Pediatrics 2015;135:e238-e254.

24 Wilson CM, Ells AL, Fielder AR. The challenge of screening for retinopathy of prematurity. Clin Perinatol 2013:40:241-59.

25 Zin AA, Magluta C, Pinto MTF, et al. Retinopathy of prematurity screening and treatment cost in Brazil. Rev Panam Salud Publica 2014;36:37-43.

26 El-Khuffash AF, McNamara PJ. Neonatologistperformed functional echocardiography in the neonatal intensive care unit. Semin Fetal Neonatal Med 2011;16:50-60.

27 Sehgal A, Mehta S, Evans N, et al. Cardiac sonography by the neonatologist: clinical usefulness and educational perspective. J Ultrasound Med 2014;33:1401-6.

28 Evans N, Gournay V, Cabanas F, et al. Point-of-care ultrasound in the neonatal intensive care unit: international perspectives. Semin Fetal Neonatal Med 2011;16:61-8. 